Indexed by

\title{
SCOPUS' GREEN LAST MILE DISTRIBUTION SYSTEM:
HETEROGENEOUS FLEET VEHICLE ROUTING PROBLEM WITH TIME WINDOW AND EXTERNAL COST
}

Crossref

$\mathrm{R} \odot \mathrm{AD}$

KOBSON

\section{Nahry Nahry}

Universitas Indonesia,

Faculty of Engineering,

Department of Civil Engineering,

Depok, Indonesia

\author{
Talitha Ayu \\ Universitas Indonesia, \\ Faculty of Engineering, \\ Department of Civil Engineering, \\ Depok, Indonesia
}

Key words: last mile delivery, logistic distribution system, vehicle routing problem, external cost

Cite article:

Nahry, N., \& Talitha, A. [2021]. Green last mile distribution system: heterogeneous fleet vehicle routing problem with time window and external cost. Journal of Applied Engineering Science, 19(1) 154 - 161. DOI:10.5937/jaes0-27922

81 Google

Online aceess of full paper is available at: www.engineeringscience.rs/browse-issues 


\title{
GREEN LAST MILE DISTRIBUTION SYSTEM: HETEROGENEOUS FLEET VEHICLE ROUTING PROBLEM WITH TIME WINDOW AND EXTERNAL COST
}

\author{
Nahry Nahry*, Talitha Ayu \\ Universitas Indonesia, Faculty of Engineering, Department of Civil Engineering, Depok, Indonesia
}

The development of e-commerce business in Jakarta, Indonesia, in recent years has made the Last Mile Delivery (LMD) business sector develop rapidly. Increased demand for LMD makes the resulting kilometer trips even greater, resulting in negative externalities. On the other hand, logistics costs in Indonesia are only affected by vehicle operating costs and no external cost component. Optimization of LMD services that take into account internal and external costs is needed to minimize the total cost of $L M D$ and in reducing the impact of negative externalities. The purpose of this paper is to optimize the LMD distribution system on the Heterogeneous Fleet Vehicle Routing Problem with Time Window and External Costs (HFVRPTW-EC) models. The optimization is done by applying the HFVRPTW-EC model using data from one of the parcel deliveries companies in Jakarta and then doing a simulation by forming several operational scenarios. The results show that the optimization of $L M D$ has reduced internal and external costs by more than $50 \%$ compared to existing conditions. The detailed results show that, for the short-term program, a scenario with a one-tier distribution system and type of motorcycle vehicle can reduce total costs compared to existing conditions by $66.22 \%$ on a peak day and $59.41 \%$ on off-peak day. Whereas for long-term program optimization, scenarios with multiple tier distribution systems and types of motorized vehicles for drop mileage and pick up truck for stem mileage can reduce total costs by $69.23 \%$ on a peak day and $60.24 \%$ on off-peak day.

Key words: last mile delivery, logistic distribution system, vehicle routing problem, external cost

\section{INTRODUCTION}

E-commerce business in Indonesia has experienced a very positive development with a transaction volume of 23 billion US\$ in 2019 and was predicted to reach 35 billion US $\$$ in 2020 [1]. The development of e-commerce business directly affects other business fields, namely Last Mile Delivery Service (LMDS) [2]. Last Mile Delivery is defined as the final part of the whole process of goods shipment from the last transit point to the point of delivery [3].

The increasing transaction volume of the e-commerce business increases the demand for LMDS users, thus generating longer kilometer trips [4]. LMDS activities with a large travel frequency can cause negative externalities. A negative externality is the negative impact of activity of a party that harms another party without compensation of the affected party [5]. Negative externalities can be noise, air pollution, accidents, safety and congestion [6]. Urban areas are the most sensitive to the negative impacts of transportation [7]. Urban transportation in Jakarta contributes $12 \%$ of total $\mathrm{CO}_{2}$ emissions nationally and $90 \%$ of air pollution of $\mathrm{CO}, \mathrm{HC}, \mathrm{NOx}, \mathrm{SOx}, \mathrm{PM}, \mathrm{O}_{3}$ substances comes from road transportation [8].

On the other hand, logistics costs in Indonesia are only influenced by internal costs, namely vehicle operating costs [9]. It is known that there is no external cost component in vehicle operating costs.

LMD services optimization that takes into account two important components. Namely internal costs and external costs is needed to minimize the total cost of LMD while simultaneously reducing the impact of negative externalities. Transportation researchers and planners have paid considerable attention to route optimization without considering environmental impacts, even though the negative externalities of shipment transportation have been very troubling [10].

One of LMD service optimization is the optimization of the distribution system [11]. Distribution system optimization is a solution of the Vehicle Routing Problem (VRP), which is a characteristic problem where minimum costs and travel times are desired with optimum travel routes [12]. VRP is one of the most frequently encountered problems in the logistics optimization process [13]. Distribution system optimization is carried out only on LMD activities, especially at the B2C or end-user level. Factors that influence the optimization of the distribution system on the LMD depend on several things, including the location of the depot and consumer, the number of vehicles available at the depot, the capacity of each vehicle, the time span of delivery/time window and road network conditions [14]. Heterogeneous Fleet Vehicle Routing Problem is one variation of VRP, modification is done by adding time window components and external costs so that it becomes the new variation, namely Heterogeneous Fleet Vehicle Routing Problem with Time Window and External Costs or abbreviated as HFVRPTW-EC.

The purpose of this paper is to optimize the last mile delivery distribution system on the HFVRPTW-EC model. This paper is organized in the following order: Section 2 is a methodology that includes data sources, mathemat- 
ical models, and software tools. Section 3 presents the results of scenario optimization and scenario evaluation. Section 4 summarizes the research and identifies the directions for further research.

\section{METHODOLOGY}

In this paper, optimization of the LMD distribution system is carried out by applying the HFVRPTW-EC model using data from one of the unnamed parcel delivery companies in Jakarta for privacy purposes and then carrying out simulations by forming several operational scenarios. The type of LMD service is specialized in the same day delivery service considering that the service has developed very rapidly in Jakarta in the last few years [15]. Data include depot and end user location (latitude and longitude), number of vehicle, vehicle type, vehicle capacity, service time, earliest start time and latest end time (time window).

The number of depots that is analyzed is only one depot with a number of demand points. The data consist of seven days starting from Monday to Sunday. Figure 1 describes the number of demands and the number of vehicles used. Total number of data analysed is represented by total number of demand within 7 days, i.e 1514 point of demand. The type of vehicle used for the existing conditions is a motorcycle (V1), but in the optimization scenario the pick-up truck (V2) is also used. Regarding the latitude and longitude data, in software applications they do not need to be converted into other forms. The vehicle capacity of a motorcycle (V1) is set to a maximum of 10 packages, while for a pick-up truck (V2) is 100 packages. The average service time of all data is 1 minute so that for the analysis the service time is set to 1 minute. The time window starts at 8:00 (earliest start time) to 22:00 (latest end time).

The first stage is developing a mathematical model for HFVRPTW-EC. A more detailed explanation for developing a mathematical model is presented in section 2.1 . The second stage is scenario development planning. The scenarios developed include variations in the distribution system and the type of vehicle used. The distribution system analyzed is one-tier system, two-tier system and multiple-tier system, while the type of vehicle analyzed is $\mathrm{V} 1$, which is a motorcycle and $\mathrm{V} 2$, a pick

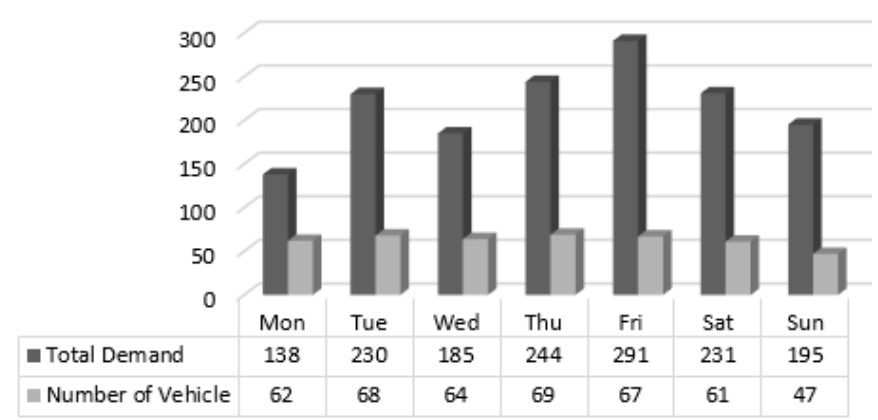

Figure 1: Total Demand (End User) and Number of Vehicle up truck. According to [16], one-tier distribution system is the movement of goods from the distribution center (DC) or depot directly to end users or point of demand (POD). One-tier distribution system does not use hub in its operation whereas a two-tier distribution system does. The two-tier system is a distribution system from DC to Hub/Intermediate Depot (ID), called stem mileage, and from ID to POD, called drop mileage. The ID functions to provide a better level of service because of fewer pointto-point demands and it can reduce travel costs, whereas the multi-tier distribution system is a combination of the one-tier and the two-tier system. Distribution systems from one-tier, two-tier and multiple-tier are only related to the distribution pattern of goods on a physical network or transportation network. Illustrations of the three distribution systems are shown in Figure 2.

The third stage is application model with software. The software used is VRP Spreadsheet Solver from [13]. A more detailed explanation regarding the VRP Spreadsheet Solver is presented in Section 2.2. The output from the VRP Spreadsheet Solver is a vehicle kilometers traveled or VKT. Calculations for estimated costs based on the cost index refer to [7], which is explained by Equation 1 as follow:

$\mathrm{E}=\frac{E C_{m} . V K T_{i}}{n_{i}}$

Based on Equation 1, (E) is the average cost of each vehicle per parcel; $(\mathrm{ECm})$ is a cost index; (VKTi) is the length of each vehicle traveled in kilometers; ( $\mathrm{ni}$ ) is the number of stops or the number of end users. ECm value or cost index for the internal cost index is obtained through the calculation of vehicle operating costs in 2020. While the external cost index for urban areas is obtained from [17]. Negative externalities considered in the external cost index are air pollution, which includes substances $\mathrm{H} 3, \mathrm{NMVOC}, \mathrm{SO}_{2}, \mathrm{NOx}, \mathrm{PM} 2.5$ and PM10 for urban areas. Use of indexes from [17] is done because in Indonesia or Asia there is no external cost index

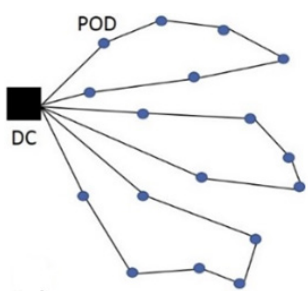

(a)

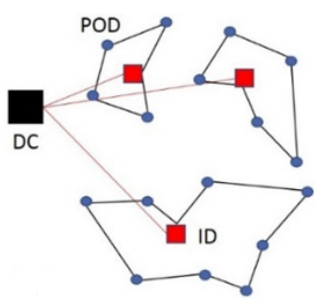

(b)

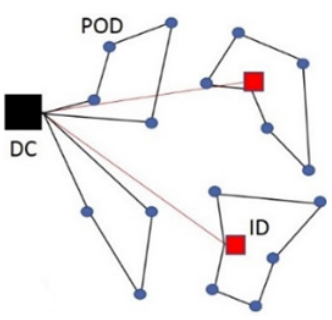

(c)

Figure 2: Distribution system (a) one tier system; (b) two tier system; dan (c) multiple tier system 
Table 1: Hyperelastic material coefficients of the healthy and atherosclerotic artery [5]

\begin{tabular}{|c|c|c|c|c|}
\hline \multicolumn{5}{|c|}{ Cost Index } \\
\hline \multirow[b]{2}{*}{ Mode } & \multicolumn{2}{|c|}{ External } & \multicolumn{2}{|c|}{ Internal } \\
\hline & (IDR/km) & (USD/km) & (IDR/km) & (USD/km) \\
\hline V1 & IDR 304 & USD 0,02 & IDR 1,970 & USD 0,13 \\
\hline V2 & IDR 526 & USD 0,04 & IDR 3,319 & USD 0,23 \\
\hline
\end{tabular}

standard. That is because, especially in Indonesia, the logistics operators have not paid too much attention to the environment. The following are the assumptions of the external and internal cost index used in this paper.

The fourth step is to analyze the comparison of the existing total cost with scenarios and evaluate the best scenarios based on the objective function. A scenario evaluation is carried out to get the most optimum scenario on the HFVRPTW-EC.

\section{Mathematical Model of HFVRPTW-EC}

The Heterogeneous Fleet Vehicle Routing Problem with time windows and external costs or HFVRPTW-EC can be defined as a problem of route optimization to minimize internal costs and external costs. The formulation of the HFVRPTW-EC mathematical model begins by defining an objective function and then forming a constraint. Let $N=\{0,1,2, \ldots, n, n+1\}$ be the set of customers and the depot $(0$ and $n+1$ correspond to the depot) and $\forall i j \in \mathrm{N}$. i is the origin of the trip and $j$ is the destination of the trip. $k$ is a vehicle of one type of vehicle $m$, where $k=\{0,1$, $\left.2, \ldots, K_{m}\right\}$ and $k \in K_{m} . K m$ is a set of vehicles for each type of vehicle. Vehicle type $m=\{0,1,2, \ldots, M\}$ and $m \in M$ where $M$ is a set of different types of vehicles. The following is the formulation of the HFVRPTW-EC mathematical model.

$\operatorname{Min} Z=\sum_{\substack{m=1 \\ m \in M}}^{M} \sum_{\substack{k=1 \\ k \in K_{m}}}^{K_{m}} \sum_{i=0}^{n} \sum_{j=1}^{n+1}\left(\alpha_{m} \cdot c_{i j k m} \cdot X_{i j k m}+\beta_{m} \cdot c_{i j k m} \cdot X_{i j k m}\right)$

Subject to:

$\sum_{\substack{m=1 \\ m \in M}}^{M} \sum_{\substack{k=1 \\ k \in K_{m}}}^{K_{m}} \sum_{i=0}^{n} X_{i j k m}=1 \quad ; \forall j \in N ; N \neq 0$

$\sum_{\substack{m=1 \\ m \in M}}^{M} \sum_{\substack{k=1 \\ k \in K_{m}}}^{K_{m}} \sum_{j=0}^{n+1} X_{i j k m}=1 \quad ; \forall i \in N ; N \neq 0$

$\sum_{j=1}^{n+1} X_{o j k m} \leq 1$

$; \forall k \in K_{m} ; \forall m \in M$

$\sum_{i=0}^{n} X_{i(n+1) k m} \leq 1$

$; \forall k \in K_{m} ; \forall m \in M$ $\sum_{i=0}^{n} X_{i k m g}-\sum_{j=1}^{n+1} X_{j k m g}=0 \quad ; \forall g \in N$

$\sum_{i=0}^{n} \sum_{j=1}^{n+1} d_{j} . X_{i j k m} \leq Q_{m}$

$; \forall k \in K_{m} ; \forall m \in M$

$t_{s} \leq t_{o k}$

$t_{o k}^{\prime} \leq t_{e}$

$t_{o k}^{\prime}=t_{o k}+\sum_{i=0}^{n} \sum_{j=1}^{n+1}\left\{t_{i j k m}+t_{c j}\right\} ; \forall k \in K_{m} ; \forall m \in M$

$x_{i j k} \in\{0,1\}$

$; \forall i j \in N ; \forall k \in K_{m} ; \forall m \in M$

The objective of HFVRPTW-EC is minimizing the total cost of $Z$ which includes internal and external costs. Internal costs are derived from the multiplication between the internal cost index $\alpha_{m}$ with a total trip length $c_{i j k m}$. Similar to external costs, which is the multiplication of external cost index $\beta_{m}$ with $c_{i j k m}$. The total length of the trip is the sum of the trip length of each vehicle $\mathrm{k}$ with the type of vehicle $\mathrm{m}$.

Constraints (3) and (4) show that each customer is visited only once. Constraints (5) indicate that all vehicles start from the depot while constraints (6) indicate that all vehicles end to the depot. Constraints (7) is the balance of vehicle currents where the amount of current entering the depot minus the amount of current leaving the depot must be equal to $0, \mathrm{~g}$ represents the current of the vehicle. Constraints (8) is the carrying capacity of a vehicle $k, d_{i}$ is the number of customer packages $j$ and $Q_{m}$ is the maximum number of package types of vehicle k. Constraints (9), (10) and (11) are the time window constraints where $t_{s}$ is the earliest time to start operating an LMD vehicle; $t_{e}$ is the latest time to start operating an LMD vehicle; $t_{c i}$ is the loading time and waiting time for the customer $j$; tok is the earliest time of departure from the depot; $\mathrm{t}_{\mathrm{ok}}$ is the latest arrival time to the depot; and $t_{i \mathrm{ikm}}$ represents the travel time of the vehicle $\mathrm{k}$ from the location $i$ to location $j$. Constraint (12) is a binary that is only 0 or 1 ; if $X_{i k m}=1$ then the route $i j$ is passed by vehicle $k$ of vehicle type $m$, and vice versa.

\section{VRP Spreadsheet Solver}

VRP Spreadsheet Solver from [13] is an open source software for vehicle routing problems. VRP Solver is operated on Microsoft Excel Add-In using the Visual Basic for Applications (VBA) programming language and the use of public Geographical Information Systems (GIS). Using the VBA programming language makes VRP solver easier to use, flexible and easily accessible.

VRP solver has a slightly different mathematical model from the mathematical model that has been developed in sub-section 2.2. The objective function of the VRP solver [13] is maximizing total profit minus vehicle travel costs, vehicle fixed costs and penalty fees for time windows. In determining travel costs $\mathrm{c}_{\mathrm{ijk}}$ there is a component of trip 
length (kilometers) multiplied by a cost index to produce travel costs. Therefore, in this paper, VRP solver functions to determine the length of the trip or VKT of each type of vehicle.

The algorithm used in the VRP solver is a metaheuristic algorithm i.e Large Neighborhood Search (LNS). Many metaheuristic algorithms have been proposed in the last decade, the most successful are Large Neighborhood Search [18], Iterated Local Search [19] and Genetic Algorithms [20]. The VRP Solver console consists of five parts: location, distance, vehicle, solution and visualization. Console location consists of address, latitude, longitude, time window, service time, pickup and delivery amount. Console distance consists of origin, destination, distance and duration. Console vehicles consist of the vehicle ID, capacity, cost per unit distance, duration multiplier, distance limit, work time limit, driving time limit, and the number of vehicles. The console solution consists of the location name, distance traveled, driving time, arrival time, departure time and working time. Console visualization is a depiction of the Bing map that shows locations (depots and customers) and vehicle routes.

\section{RESULTS AND DISCUSSIONS}

The application model with software consists of existing conditions and scenarios. The existing conditions have a one-tier distribution system with $\mathrm{V} 1$ vehicle type. The time window starts at 8:00 to 22:00. The application of existing conditions with VRP solver is carried out for one week starting from Monday to Sunday. Figure 3 presents the results of the model application for existing conditions in one week.

The heaviest condition is defined with the largest VKT value while the lightest condition is defined otherwise. Based on Figure 3, the toughest condition is Friday with a VKT value of $1432.55 \mathrm{~km}$ and the lightest condition is Sunday with a VKT value of $898.68 \mathrm{~km}$. In addition, the number demand for Friday has the highest number compared to other days. Thus, for further analysis, the peak condition $i$ is Friday and the off-peak condition is Sunday. Friday produces the largest VKT value, it can be said to be reasonable considering that Friday is the last day before the weekend so that the demand for same day package delivery will increase. While Sunday produces the lowest VKT value because Sunday is the last

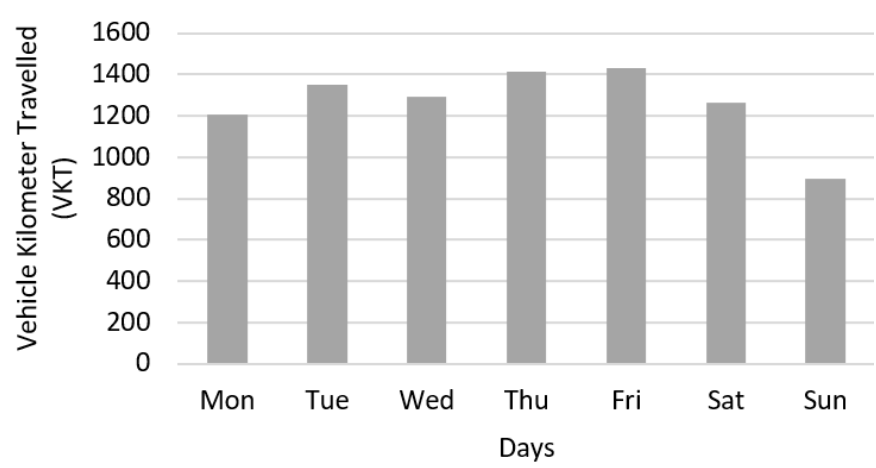

Figure 3: VKT for Existing Condition day to weekday or to Monday so the demand for same day package delivery will decrease.

\section{SCENARIO}

From the peak and off-peak conditions based on the previous analysis, several scenarios, which include a combination of distribution systems and combinations of vehicle types were made. The following is the distribution system and vehicle type for each scenario presented in Table 2.

Table 2: Scenario Planning

\begin{tabular}{|c|c|c|}
\hline Scenario & Type of Vehicle & Distribution System \\
\hline Existing & V1 & One Tier System \\
\hline SK-1 & V1 & One Tier System \\
\hline SK-1 & V2 & One Tier System \\
\hline SK-1 & V1 \& V2 & One Tier System \\
\hline SK-1 & V1 & Two Tier System \\
\hline SK-1 & V2 & Two Tier System \\
\hline SK-1 & V1 \& V2 & Two Tier System \\
\hline SK-1 & V1 & Multi Tier System \\
\hline SK-1 & V2 & Multi Tier System \\
\hline
\end{tabular}

For the two-tier and multiple-tier distribution systems, there are two parts of the distribution system analyzed, namely stem mileage or from DC to ID and drop mileage or from ID to POD. In defining the location of the ID, the zoning system approach is carried out as follows:
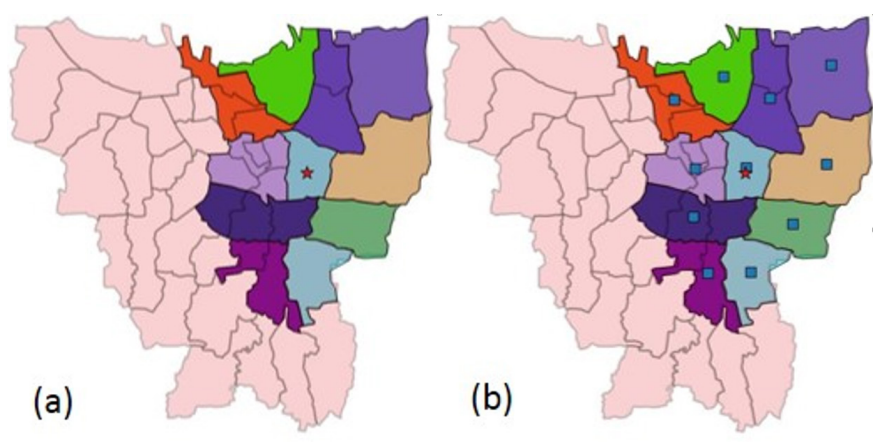

Figure 4: (a) Zoning System; and (b) Hub/ID Location

Based on Figure 4, the zoning system is carried out in accordance with the administrative area of the sub-district in Jakarta. Star symbol is the location of a depot (DC) and the colored region is the location of each zone. Each zone can consist of one sub-district or a combination of several sub-districts. The main consideration of the formation of zones is based on the wide area of the district. Next, each zone is searched for its centroid point so that the hub location (ID) for each zone can be known. In mapping the zoning system, it is assisted with QGIS software. 


\section{ANALYSIS AND SCENARIO EVALUATION}

Based on the results of the model application using VRP Solver, the value of vehicle kilometers traveled (VKT) for each scenario for each type of vehicle can be known. Using Equation 1, internal, external and total costs can be identified for each scenario. Figure 5 shows the VKT value for each scenario. Figure 6 shows the results of external costs for each scenario, Figure 7 shows the results of internal costs, Figure 8 shows the total cost for peak day condition and Figure 9 shows the total cost for off-peak day condition. Total cost is the sum of internal and external costs.

The VKT values in Figure 5 are categorized based on the type of vehicle and categorized based on the type of day (peak day and off-peak day). Nine scenarios that have been carried out produce a smaller VKT value than existing conditions, both for peak day and off-peak day conditions. Some scenario consists of one type of vehicle, some consists of a combination of two types of vehicles, this is in accordance with the scenario planning in Table 2.

Based on the external cost analysis in Figure 6, it can be seen that SK-7 occupies the lowest external cost compared to other scenarios for both peak day and off-peak day. In SK-7, a multiple-tier distribution system is applied with the type of vehicle used for drop mileage is a motorcycle (V1) while the type of vehicle for the stem mileage is pick up truck (V2). SK-7 can reduce external costs compared to existing conditions by $69.04 \%$ (peak day) and $59.97 \%$ (off-peak day). SK-7 ranks first as the lowest external cost, because in SK-7 a multi-tier distribution system is applied where the hub/ID is used in its opera-

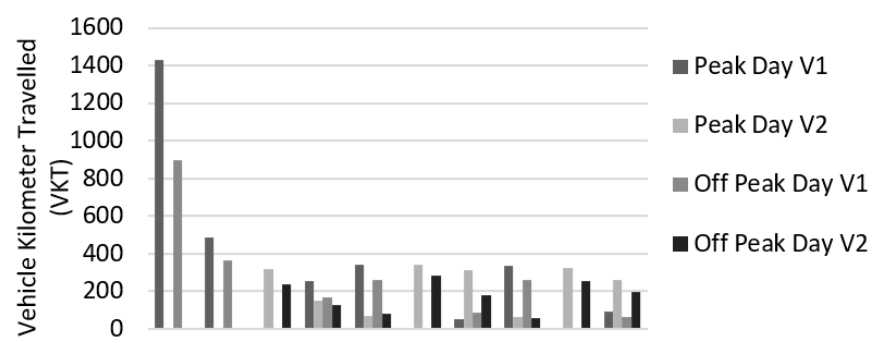

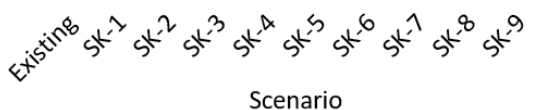

Figure 5: Vehicle Kilometer Travelled (VKT)

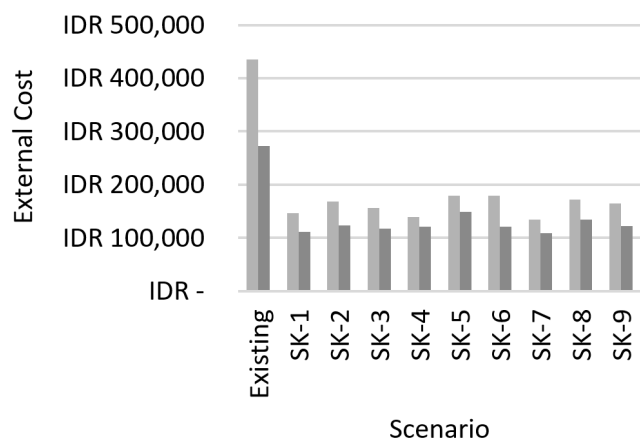

Figure 6: External Cost tion. The use of ID can provide a better level of service because of the lower point-to-point demand to reduce external costs. The second lowest external costs rank is occupied by SK-4 (peak day) and SK-1 (off-peak day) with a reduction in external costs compared to existing conditions by $67.94 \%$ (peak day) and $59.41 \%$ (off-peak day). Based on the number of hubs, SK-7 and SK-4 on peak day conditions have the same distribution of hub locations, amounting to eight hubs. While the number of hubs on SK-7 off-peak day is seven hubs. The number of peak day hubs is more than the off-peak day, this is due to the number of peak day demand is greater than the off-peak day.

The analysis of internal costs in Figure 7 shows similar results to the analysis of external costs. The lowest internal costs was achieved by SK-7 with a reduction compared to the existing conditions of $69.26 \%$ (peak day) and $60.28 \%$ (off-peak day). The second lowest internal costs were occupied by SK-4 (peak day) and SK-1 (off-peak day) with a reduction compared to the existing conditions of $68.17 \%$ (peak day) and $59.41 \%$ (off-peak day). The similarity ranking of scenario that produces the lowest external and internal costs due to the analysis conducted is linear in accordance with Equation 1 and because the internal and external cost index for each type of vehicle has a ratio that is not much different. The ratio $\mathrm{V} 1 / \mathrm{V} 2$ for internal costs is 0,59 whereas the ratio of $V 1 / \mathrm{V} 2$ for external costs is 0.57 . A small difference in the ratio of only $3.3 \%$ results in the same sequence of scenarios between internal and external cost analysis. The scenario with the largest internal cost is SK-5, the scenario with the worst internal cost condition is still far better than the existing internal cost condition. SK-5 can reduce internal costs compared to existing conditions by $58.88 \%$ (peak day) and $45.48 \%$ (off-peak day). Existing conditions produce internal and external costs that are far greater than the scenario. This is due to the route operation that does not use route optimization with time windows. Logistics operators tend to be in a hurry in delivering goods, resulting in very large operational costs. In general, the difference in the reduction of external costs for the two conditions, namely peak day and off-peak day, is not too different

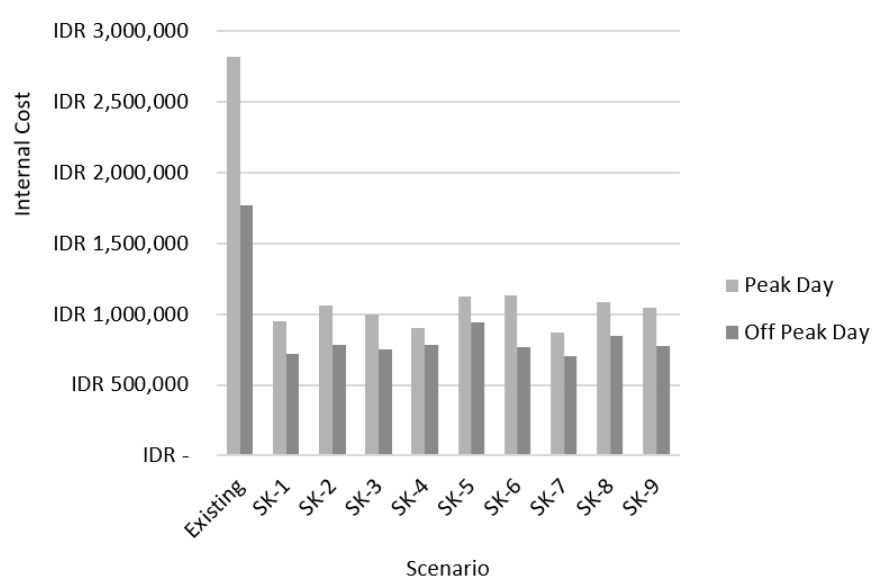

Figure 7: Internal Cost 
and results in values above $50 \%$, so that the application of the optimization scenario is compared to the existing conditions results in much better conditions.

The analysis of total cost in peak day conditions in Figure 8 shows that SK-7 ranks first on lowest total cost compared to existing condition, which is equal to $69.23 \%$. That is because SK-7 uses a multi tier distribution system where ID is used as a hub to reduce distance while reducing total costs given the lower point-to-point demand. In addition, SK-7 also uses the type of vehicle V1 at the drop mileage and V2 on the stem mileage. Drop mileage results in a greater trip length than stem mileage, so for larger trips, the V1 type of vehicle has a lower cost index than V2. While the stem mileage, even though using a V2 type of vehicle, only requires 1 unit of the vehicle in its operation. The second lowest total cost is SK-4 with a reduction in total cost compared to existing conditions of $68.14 \%$. while the third rank is SK-1 with a reduction in total costs compared to existing conditions by $66.22 \%$. SK-1 is the closest scenario to existing conditions by applying a one-tier system distribution system and using one type of vehicle, V1. In the absence of changes in the distribution system and vehicle type, route optimization results in a lower total cost on SK-1 of $66.22 \%$ compared to existing conditions.

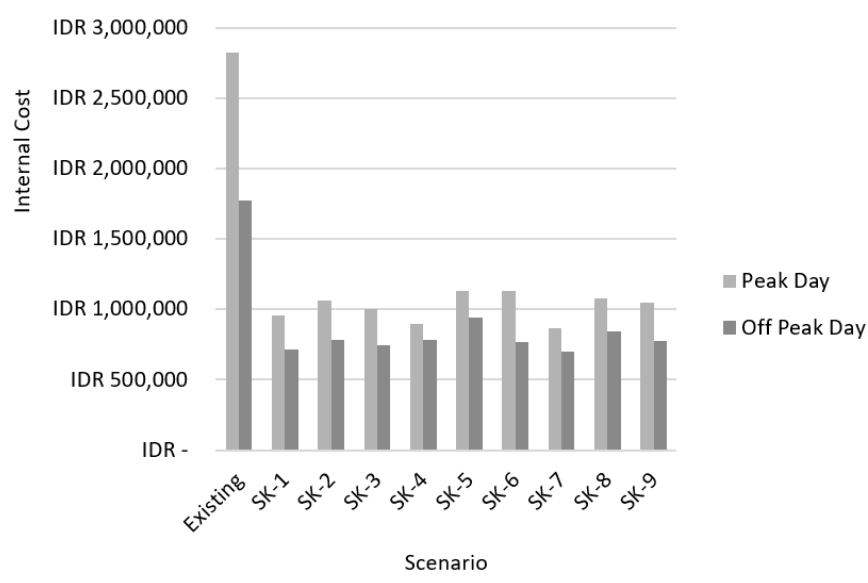

Figure 8: Total Cost - Peak Day
For off-peak day conditions, the sequence ranking scenario is slightly different from the peak day conditions. The first rank is occupied by SK-7 with a reduction in total costs compared to existing conditions by $60.24 \%$. The second rank is occupied by SK-1 with a reduction in total costs by $59.41 \%$ and the third rank is occupied by SK-3 with a reduction in total costs by $57.67 \%$. From the two conditions, namely peak day and off-peak day, SK-7 and SK-1 occupy the three highest ranking of the lowest total costs. Although based on SK-7 analysis, the total cost is lower than SK-1. Both scenarios can be considered to be the chosen scenario based on the objective function, namely the minimum internal costs and external costs.

According to the analysis that has been done, if the optimization is done for a short-term program, SK-1 is the best scenario considering there is no need for large investment costs for the construction of hubs and procurement of V2 vehicles. In this case, optimization is only carried out on the operational part, which uses V1 vehicle type and one tier distribution system according to the existing conditions. As for the long-term optimization program, SK-7 is the best scenario considering the existence of a hub makes a point to point demand smaller so that the level of service is better and results in a minimum total cost.

\section{CONCLUSIONS AND FUTURE REMARKS}

The most optimal last mile delivery distribution system for the Heterogeneous Fleet Vehicle Routing Problem with Time Window and External Costs or HFVRPTW-EC based on a case study from one parcel delivery company in Jakarta is categorized into two: (a) For the short-term programs, SK-1 is the best solution by only optimizing the operational side. SK-1 can reduce total costs compared to existing conditions by $66.22 \%$ on peak day and $59.41 \%$ on off-peak day. (b) For the long-term program, SK-7 is a solution that can be chosen considering the investment costs from the construction of the hub and the procurement of vehicles which is quite large. SK-7 can reduce total costs by $69.23 \%$ on peak day and $60.24 \%$ on off-peak day. Hub consolidation can add to shipping and transportation utilities, have a fixed cost component

IDR 2.500.000

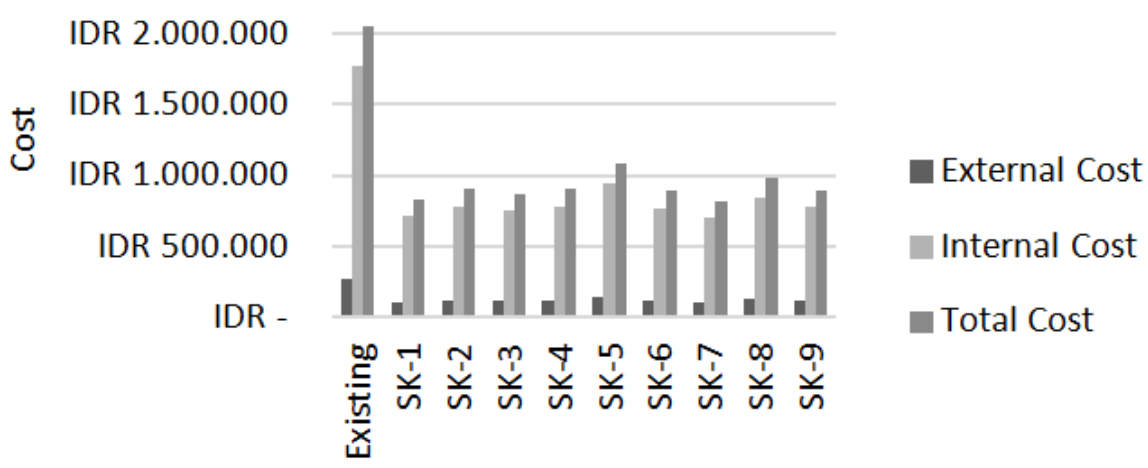

Scenario

Figure 9: Total Cost - Off-Peak Day 
per shipment and provide a better level of service given the shorter point to point demand [16]. The following is an illustration of vehicle routing of SK-1 and SK-7 during peak day and off-peak day conditions.

By optimizing the distribution system and vehicle type, the scenario results show that internal costs are much lower compared to existing conditions. This is also in line with the VKT value of the scenario result, which is much shorter than the existing condition, so that the fewer kilometers traveled, the less the impact of externalities felt by the public [4]. In addition to reducing operational costs, the optimization of the distribution system can also reduce the negative impact of air pollution in urban areas, which has been unsettling for the public so far. So it can be said that optimization is not only

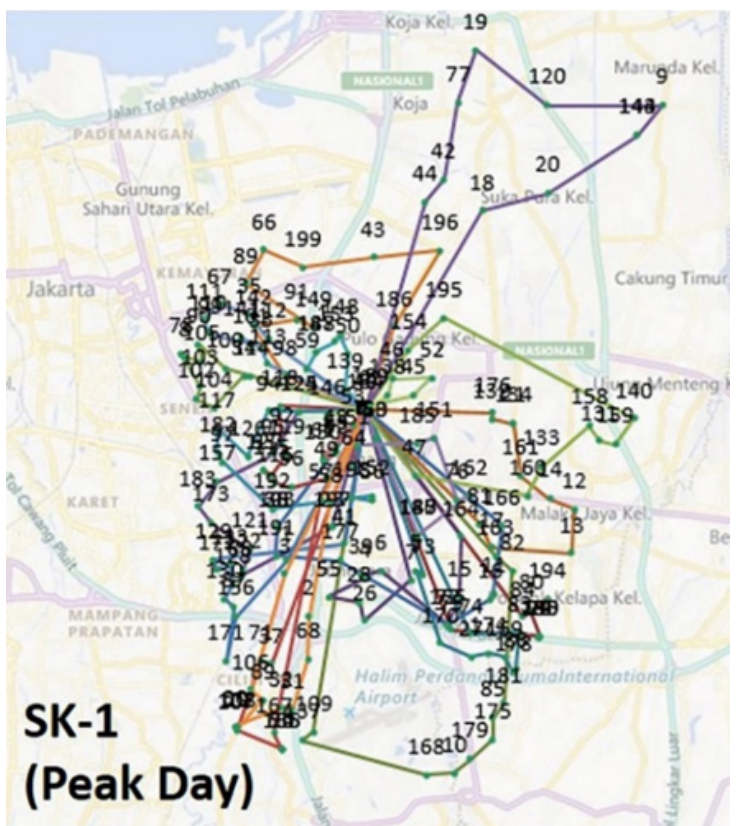

(a)

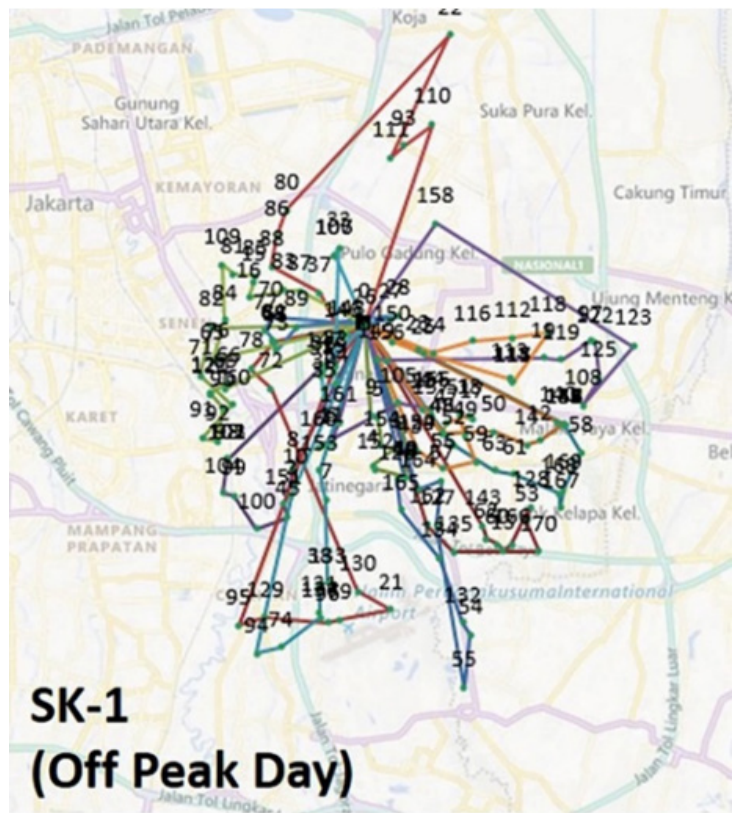

(b)

Figure 10: Vehicle Routing for SK-1

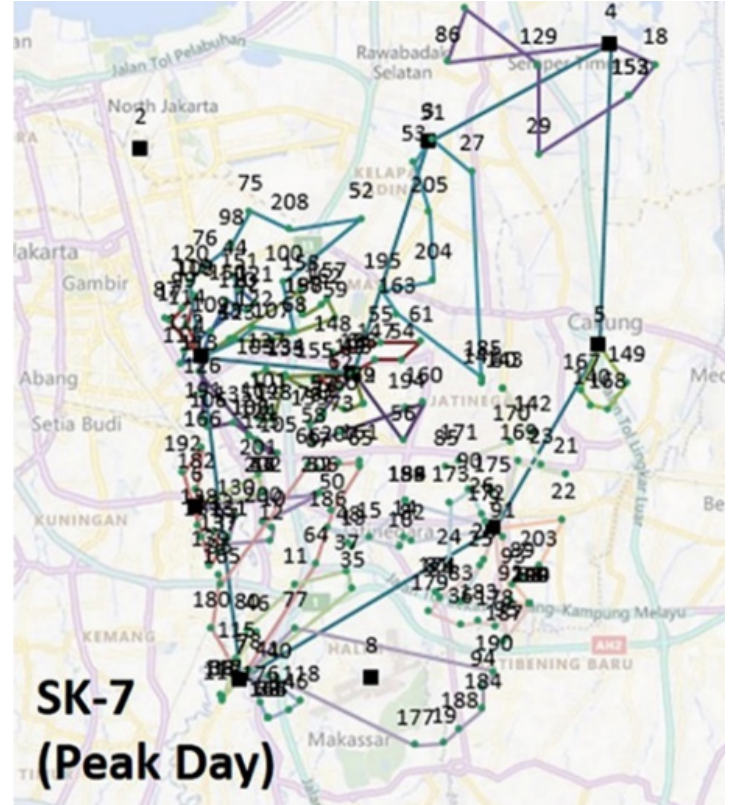

(a)

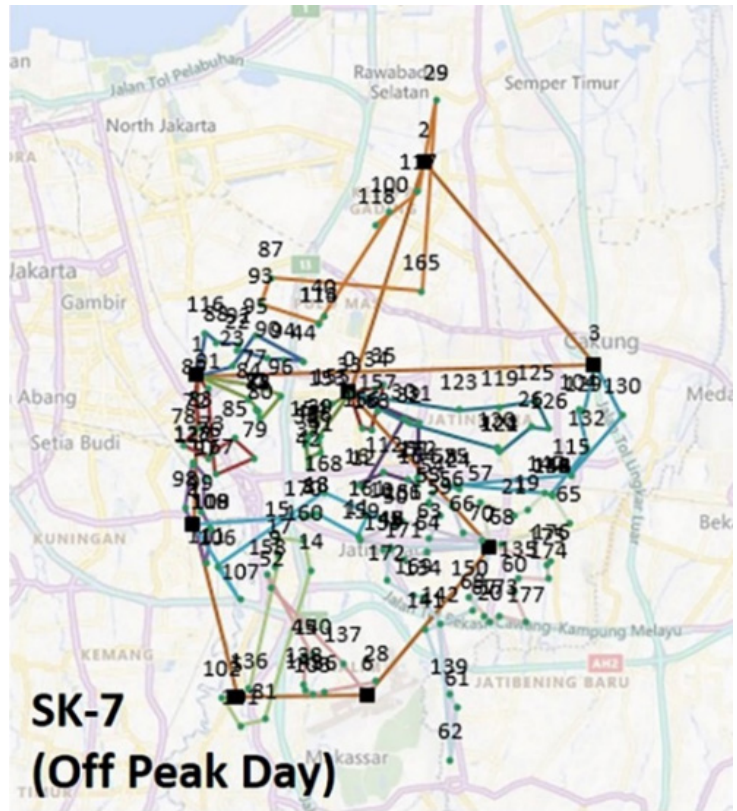

(b)

Figure 11: Vehicle Routing for SK-7

important for logistics operators in reducing operating costs but also important in sustainable urban planning. Some previous studies have also succeeded in developing optimization models for vehicle routing problems such as [21] which can reduce $20 \%$ - $30 \%$ of total costs, including the cost of fuel emissions and $\mathrm{CO}_{2}$ emissions. Moreover, [22] also managed to reduce total costs including external costs by $9 \%-44 \%$. Research related to vehicle routing problems in LMD that considers negative externalities is important to be further developed to create sustainable urban logistics transportation.

Limitations on this paper can be developed for future research. The optimization of the LMD on the HFVRPTWEC model by using an external cost index according to conditions in Jakarta can be further investigated to ob- 
tain model results that are far more indicative of the actual conditions in terms of external costs and also in terms of the impact of externalities generated. In addition, LMD optimization for the HFVRPTW-EC model that involves investment costs for hub development and vehicle procurement can also be further researched.

\section{ACKNOWLEDGMENT}

This research is supported by the Research Fund of PUTI (Publikasi Terindeks Internasional Prosiding) of Universitas Indonesia, Contract No. NKB-1062/UN2. RST/HKP05.00/2020 dated 29 April 2020.

\section{REFERENCE}

1. Redseer (2020). Report On Indonesia ECommerce, Metamorphosis in a Post Covid World. Redseer, Jakarta.

2. Ozan, Sahiner. E-Commerce Impact On Logistics, More Than Shipping. from https://www.morethanshipping.com/e-commerce-impact-on-logistics/, accessed on 2020-03-01.

3. Lindner, J. (2011). Last Mile Logistics Capability: a Multidimensional System Requirements Analysis for a General Modelling and Evaluation Approach.

4. Taniguchi, E., \& Kakimoto Y. (2004). Modelling effects of e-commerce on urban freight transport. Logist. Syst. suistanable cities, vol. 1, 35-46, DOI: 10.1016/B978-008044260-0/50012-X.

5. Brons, M., Christidis P. (2012). External Cost Calculator for Marco Polo Freight Transport Project Proposals. Spain. DOI: 10.2791/93232.

6. Demir E, Huang Y, Scholts S, Van Woensel T. (2015). A selected review on the negative externalities of the freight transportation: Modeling and pricing. Transp Res Part E Logist Transp, vol 77, 95-114. DOI: 10.1016/j.tre.2015.02.020.

7. Cárdenas I, Beckers J, Vanelslander T. (2017). E-commerce last-mile in Belgium: Developing an external cost delivery index. Res Transp Bus Manag, vol. 24, no. 12, 3-9, DOI: 10.1016/j.rtbm.2017.07.006.

8. Yudha SW. (2017). Air Pollution And Its Implications For Indonesia: Challenges And Imperatives For Change. Jakarta.

9. Zaroni. Biaya Logistik Agregat, from http://supplychainindonesia.com/new/biaya-logistik-agregat/, accessed on 2020-03-05.

10. Serrano-hernández $A$, Alvarez $P$, Lerga I, Reyes-rubiano L. (2017). Pricing and Internalizing Noise Externalities in Road Freight Transportation. Transp Res, vol. 27, no. 3, 25-32, DOI: 10.1016/j.trpro.2017.12.059.

11. Janjevic M, Winkenbach M, Merchan D. (2019). Integrating collection-and-delivery points in the strategic design of urban last-mile e-commerce distribution networks. Transp Res Part E, vol. 131, 37-67, DOI: 10.1016/j.tre.2019.09.001.
12. Irnich, S., Toth, P., Vigo D. (2014). Chapter 1 The Family of Vehicle Routing Problems. Vehicle routing: problems, methods, and applications. DOI: 10.1137/1.9781611973594.ch1.

13. Erdogan, Gunes. (2017). An open source Spreadsheet Solver for Vehicle Routing Problems. Comput Oper Res, vol. 84, 62-72. DOI: 10.1016/j. cor.2017.02.022.

14. Toth, P., \& Vigo D. (2014). Vehicle routing: Problems, methods, and applications (2nd revised edition). Philadelphia: SIAM - Society for Industrial and Applied Mathematics. DOI: doi.org/1611973589.

15. Zaroni. Inovasi Logistik E-Commerce, from https:// supplychainindonesia.com/new/inovasi-logistik-e-commerce/. accessed on 2020-03-05.

16. Lab MCL. Why Last Mile Logistic, from https://megacitylab.mit.edu/why-last-mile-logistics/. accessed on 2020-03-06.

17. European Commission. (2019). Handbook on The External Costs of Transport. European Commission, Brussels.

18. Pisinger D, Ropke S. (2007). A general heuristic for vehicle routing problems. Comput Oper Res, vol. 34, 24-35. DOI: 10.1016/j.cor.2005.09.012.

19. Subramanian A, Drummond LMA, Bentes C, Ochi LS, Farias R. (2010). A parallel heuristic for the Vehicle Routing Problem with Simultaneous Pickup and Delivery. Comput Oper Res, vol. 37,no. 18, 99-111. DOI: 10.1016/j.cor.2009.10.011.

20. Vidal T, Crainic TG, Gendreau M, Prins C. (2014). A unified solution framework for multi-attribute vehicle routing problems. Eur J Oper Res, vol. 234, no. 6, 58-73. DOI: 10.1016/j.ejor.2013.09.045.

21. Niu Y, Yang Z, Chen P, Xiao J. (2018). Optimizing the green open vehicle routing problem with time windows by minimizing comprehensive routing cost. J Clean Prod, vol. 171, no. 9, 62-71. DOI: 10.1016/j. jclepro.2017.10.001.

22. Martins-turner K, Nagel K, Martins-turner K, Nagel K. (2019). How Driving Multiple Tours A ff ects the Results of Last Mile How Driving Delivery Multiple Vehicle Tours A ff ects the Results of Last Mile Routing Problems Delivery Vehicle Routing Problems. Procedia Comput Sci, vol. 151, no. 84, 0-5. DOI: 10.1016/j.procs.2019.04.115.

Paper submitted: 11.08.2020.

Paper accepted: 17.10.2020.

This is an open access article distributed under the CC BY 4.0 terms and conditions. 